\title{
ABORDAGENS DO TRABALHO NO SETOR PÚBLICO DE SAÚDE: UMA REVISÃO NARRATIVA DA LITERATURA
}

\section{APPROACHES OF WORK IN THE PUBLIC HEALTH SECTOR: A NARRATIVE REVIEW OF LITERATURE}

\author{
Marcia Teixeira' (iD (0000-0002-9502-0789), Maria Inês Carsalade Martins² iD (0000-0001-7757-449x), Isabel \\ Cristina Silva Arruda Lamarca² (iD) (0000-0002-6436-5944), Simone Oliveira ${ }^{3}$ (iD) (0000-0002-1477-749X)
}

\begin{abstract}
${ }^{1}$ Fundação Oswaldo Cruz, Escola Nacional de Saúde Pública Sergio Arouca, Departamento de Administração e Planejamento em Saúde, Rio de Janeiro, RJ, Brasil. <txmarcia47@gmail.com>

${ }^{2}$ Fundação Oswaldo Cruz, Escola Nacional de Saúde Pública Sergio Arouca, Departamento de Ciências Sociais, Rio de Janeiro, RJ, Brasil.

${ }^{3}$ Fundação Oswaldo Cruz, Escola Nacional de Saúde Pública Sergio Arouca, Centro de Estudos da Saúde do Trabalhador e Ecologia Humana, Rio de Janeiro, RJ, Brasil.
\end{abstract}

Resumo Trata-se de revisão narrativa de literatura para identificar diferentes abordagens teóricas que vêm sendo utilizadas na discussão sobre o trabalho em saúde. Nosso objetivo foi atualizar o conhecimento sobre essa temática pelo mapeamento das diferentes estratégias metodológicas. Organizou-se a bibliografia segundo três perspectivas de análise: mercado os sujeitos do trabalho vistos como força produtiva; Estado - os sujeitos do trabalho entendidos como elo entre o Estado e a sociedade; e atividade - a dimensão subjetiva do trabalho. Tal estratégia possibilitou uma visão integrada do campo, apontando os diferentes, porém complementares, caminhos metodológicos para a análise do trabalho no setor público de saúde.

Palavras-chave trabalho em saúde; mercado de trabalho em saúde; processo de trabalho em saúde; atividade em saúde; política de gestão do trabalho em saúde.
Abstract This is a narrative review of literature identifying different theoretical approaches that have been used in the discussion about health work. Our objective was to update the knowledge about this theme by mapping the different methodological strategies. The bibliography was organized according to three diferents perspectives of analysis: Market - the subjects of labor seen as a productive force, State - the subjects of labor understood as the link between State and Society, and Activity - the subjective dimension of work. This strategy made possible an integrated vision of the field, pointing out the different but complementary methodological paths for the analysis of work in the public health sector.

Keywords labor in health; labor market in health; labor process in health; activity in health; labor management policy in health. 


\section{Introdução}

O debate teórico em torno do tema trabalho em saúde está inserido em um campo multidisciplinar, o que lhe confere diferentes caminhos para investigação devido à diversidade de concepções analíticas. O aumento, nos últimos anos, da produção brasileira e internacional sobre esse tema evidencia a sua relevância e constitui uma justificativa suficiente para que propostas orientadasaodesenvolvimentodesíntesesanalíticassejamtentadas,mesmo entendendo que toda seleção, em uma vasta literatura, seja inevitavelmente incompleta.

No Brasil, o campo da pesquisa sobre o trabalho em saúde mereceu importantes revisões sobre a sua produção (Schraiber e Peduzzi, 1993; Paim, 1994; Peduzzi e Schraiber, 2000; Nogueira, 1992, 2002; Silva, 2006; Pinto et al., 2013). Apesar de estratégias de coleta de informações distintas, esses trabalhos compreendem um período de quarenta anos de sistematização dos estudos realizados na área, entre os anos de 1970 e 2010.

A produção intensificada desde década de 1970 é analisada com base no trabalho seminal de Cecília Donnangelo (1975) sobre o médico e seu mercado de trabalho. Nesse período, a temática central dos debates, segundo Pinto e colaboradores (2013), eram, por um lado, as diferentes propostas de mudança do ensino médico na América Latina e, por outro, a necessidade de reconfiguração da força de trabalho diante da emergência de novos desenhos para os sistemas de saúde.

Ao dar sequência aos estudos de Donnangelo, Mendes Gonçalves (1979), apoiado na teoria marxista, analisou o'processo de trabalho em saúde' propondo que o objeto do trabalho, a finalidade, seus instrumentos e os agentes do trabalho fossem estudados de forma articulada, configurando um processo de trabalho específico.

Na década de 1980, como indica Paim (1994), os estudos que sobressaem são filiados a uma determinada vertente de pesquisa sobre a força de trabalho em saúde, fruto de uma reunião de instituições como Organização Pan-Americana da Saúde (Opas), Instituto Brasileiro de Geografia e Estatística (IBGE), Escola Nacional de Saúde Pública Sergio Arouca (Ensp) e Ministério da Saúde, e de pesquisadores como Machado e colaboradores (1992), entre outros. Amplia-se o escopo da pesquisa do campo, agora subdividido em diversas temáticas: profissionais de saúde; formação/capacitação de recursos humanos em saúde; administração de recursos humanos em saúde; mercado de trabalho em saúde; política de recursos humanos em saúde; e agentes do trabalho em saúde (Paim, 1994).

Após revisão sistemática sobre a produção do campo, Pinto e colaboradores (2013) destacam que entre 1990 e 2010, apesar da ampliação considerável da literatura sobre trabalho e educação em saúde, a maior parte da produção 
esteve centrada na temática da formação, constituindo-se de estudos empíricos, relatos de experiência ou ensaios. Também constatam a pouca produção de trabalhos conceituais sobre o mercado de trabalho em saúde e nenhum artigo sobre a revisão de literatura para as temáticas mercado de trabalho em saúde, administração e políticas de recursos humanos em saúde nesse período.

De modo a contribuir para o 'desenvolvimento do estado da arte' nesse campo, realizou-se esta revisão narrativa de literatura, na qual identificamos diferentes abordagens teóricas que vêm sendo utilizadas na discussão sobre o trabalho em saúde, com o objetivo de atualizar o conhecimento sobre o tema, diversificar as estratégias de pesquisa e ampliar o escopo de análise, de forma a responder às novas questões que têm surgido no mundo do trabalho.

O encontro de disciplinas e abordagens parte da constatação de que nos últimos vinte anos as relações de trabalho na saúde, como em toda a administração pública brasileira, são marcadas por fenômenos vindos de um contexto nacional e internacional de reestruturação da produção, de revisão do papel do Estado e sua relação com a sociedade, além de mudanças importantes na relação homem/trabalho. Nesse período, ocorreram movimentos nos diferentes planos. No mercado de trabalho em geral, sob o paradigma da flexibilização, rompe-se com os principais compromissos sociais anteriormente consolidados (Dedecca, 1996). No modelo de gestão do Estado, influenciado pelo movimento internacional de uma 'nova gestão pública (NGP)' (Sano e Abrucio, 2008), são introduzidas novas regras, novas práticas e formas de organizar o trabalho, tanto no mercado de trabalho em geral quanto no setor público.

Essas mudanças são, ao mesmo tempo, fator de intervenção e resultado dos fenômenos que ocorrem no dia a dia do processo de trabalho, pois o inter-relacionamento desses eventos também afeta a forma de ser dos trabalhadores (Antunes, 1995). Esses três grandes movimentos exigem múltiplas abordagens de investigação e compreensão.

\section{Referencial teórico}

Oeixoteórico-metodológicoqueorientouestarevisãotomaemprestadooesquema tripolar proposto por Schwartz, Duc e Durrive (2010). Estes autores, apoiadosnaabordagemergológica, ${ }^{1}$ analisamarelaçãohomem/trabalhopor um triângulo que tem como um dos vértices o polo do'mercado', que inclui as mudanças no processo de trabalho e as novas formas de organização da produção; o polo do'político', que inclui a organização do Estado mediando as demandas sociais e as demandas do mercado; e o polo da 'atividade', expresso na atividade laboral e que resulta da tensão dos dois, mas também os influencia e pressiona (Oliveira, 2007; Oliveira, Alvarez e Brito, 2013).

Utilizar a imagem tripolar para analisar o trabalho em saúde nos estimula a pensar as diferentes escolas de pensamento e sobre como as temáticas são tratadas. Na perspectiva do mercado, os sujeitos do trabalho são compreendi- 
dos como força produtiva; do Estado, como o elo entre o Estado e a sociedade, na medida em que operacionalizam as políticas públicas; e na da atividade, o trabalho é abordado como uma prática social e os sujeitos entendidos como gestores de sua ação.

A seguir, apresentamos três seções, que tratam de cada perspectiva sobre o trabalho, seguidas das considerações finais onde se ressalta a importância de um diálogo entre elas.

\section{A perspectiva do mercado: o trabalhador como força produtiva}

Em um período anterior à flexibilização das relações de trabalho, um conjuntoimportantedeeconomiascapitalistasexperimentavaummomentode crescimentoeconômicoaliadoà expansãodeprogramasdebem-estarsocial. Especialmentenas décadas de 1950 e 1960, seguindo-seo modelokeynesiano de regulação sobre a economia, o crescimento da produção esteve acompanhado de elevação salarial e redução das taxas de desemprego.

O modelo de gestão do trabalho, baseado no controle fordista, embora com forte conflito de interesses entre capital e trabalho, pressupunha o estabelecimento de uma relação salarial de mais longo prazo, com limites às demissões, salário indexado aos preços e à produtividade geral, além do Estado-providência, que em alguns países assegurava uma renda permanente aos trabalhadores assalariados (Lipietz, 1991; Mattoso, 1996).

Em meados dos anos 1970, a crise dos países industrializados, marcada pela crise do petróleo e alterações de preços das matérias-primas, acabou por aumentar o processo inflacionário e a recessão, ampliando os questionamentos sobre o regime de acumulação fordista e, por conseguinte, o próprio modelo de relação de trabalho (Dedecca, 1996). A partir da década de 1980, o rompimento do padrão de estruturação do mercado de trabalho das economias desenvolvidas trouxe questionamentos sobre os sistemas contratuais de trabalho, e a desregulação/flexibilização das relações passou a ser a principal estratégia adotada.

Em que pesem os estudos sobre produção social e trabalho terem suas raízes teóricas nas tradições sociológicas de Durkheim, Weber e Marx, além de serem constantemente acionados por diferentes autores para a compreensão sobre os fenômenos do trabalho, o marco teórico a ser destacado é o estudo de Daniel Bell (1973) acerca da 'sociedade pós-industrial'. Publicado ainda na década de 1970, este trabalho teve forte repercussão nos estudos que se seguiram, principalmente para o conjunto de autores que passaram a defender a ideia do 'descentramento' da questão do trabalho como fenômeno social principal.

Para essa corrente de análise, a sociedade pós-industrial é marcada pela produção ascendente de serviços e descendente de bens industriais, pela sindicalização crescente de 'empregados de escritório' e funcionários públicos. A informação torna-se poder e a ciência sua base; a 'classe' mais importante 
dessa sociedade emergente seria antes de tudo a profissional, apoiada mais no conhecimento do que na propriedade (Bertero, 2005). Essas teses estiveram no centro de um movimento de revisão de modelos de análises sobre o trabalho, no qual o debate mais amplo se concentrava na atualidade ou não das tradições teóricas nas ciências sociais diante das transformações culturais, sociais e políticas (Ferreira e Costa, 1998-1999).

Da década de 1990 em diante, a temática do trabalho ganha uma nova centralidade com o movimento internacional de reestruturação da produção, que se intensifica nesse período e é a favor da flexibilização das relações de trabalho, com consequentes heterogeneidade das formas de contratação e mudanças na esfera dos direitos do trabalho e na organização dos trabalhadores.

Com a diversidade de abordagens, torna-se possível observar diferentes e muitas vezes divergentes enfoques sobre o movimento de flexibilização. Como conceito-chave para compreensão das atuais relações de trabalho, a flexibilização tem sido focalizada ou mesmo utilizada, em diversos aspectos, tanto em estudos que tratam do tema como em distintas propostas de mudanças na órbita dos mercados de trabalho.

Em uma sistematização das diferentes leituras sobre as alterações nos mercados de trabalho, Kovács (2012) identifica um debate entre a perspectiva dominante e as abordagens críticas. Para o discurso dominante, as mudanças nas relações de trabalho são focalizadas como necessidade de adaptação às condições econômicas em que tempo e jornada de trabalho, bem como sistemas salariais, devam ser ajustados às flutuações dos mercados.

Dessa forma o conceito de flexibilização do trabalho é entendido como variação do volume do emprego diante de variações de demanda global e local; sensibilidade dos salários com relação à situação das empresas; e supressão dos dispositivos legais desfavoráveis ao emprego em matéria de políticas fiscais e sociais (Boyer, 1987, apud Organización Panamericana de la Salud, 1996).

Para Kovács (2012), essa tese, de cunho neoliberal, se apoia no reforço à regulação pelo mercado e liberação dos mecanismos de regulação social visando ao dinamismo econômico, em que novas oportunidades de trabalho seriam criadas pela mercantilização de todas as atividades com menos regras e custos sobre o trabalho.

Por sua vez, os defensores das teses sobre o fim da centralidade do trabaIho sustentam que a alternativa estaria no terceiro setor, que se constitui em um lugar privilegiado para o surgimento de uma sociedade orientada para serviços e laços comunitários. As atividades autônomas, voluntárias, com a participação ativa na sociedade civil na esfera política, dariam a segurança de um rendimento estável e suficiente a todos. O pleno emprego seria substituído pela plena atividade (Kovács, 2012).

Em uma terceira perspectiva estão os estudos críticos sobre a subordinação da sociedade às leis do mercado e à lógica da globalização, o que aumenta a 
disseminação de formas instáveis de emprego, diminui a qualidade dos vínculos de trabalho com consequente risco de expansão das desigualdades sociais e a própria coesão social. Esses estudos tratam de mudanças nas relações de trabalho associadas a desigualdades no ingresso, perda de postos e precarização das condições de trabalho (Lipietz, 1991; Coriat, 1994; Antunes, 1995; Deddeca, 1996; Mattoso, 1996; Castel, 1998). Nessa linha, seria necessário o estabelecimento de alternativas orientadas para a 'renovação da sociedade do trabalho', com uma nova regulação que considere padrões e princípios globais e articule objetivos econômicos e sociais, em direção a uma 'flexibilidade humanizada' (Kovács, 2012).

As mudanças na organização da produção têm constituído um grande desafio à investigação sobre o trabalho em geral, e os estudos sobre a composição da estrutura e a dinâmica dos mercados de trabalho tornaram-se um instrumento essencial para o entendimento sobre tais mudanças e seus impactos sociais.

Para essa abordagem, são prioritários os aspectos demográficos e socioeconômicos, constituída de estudos sobre as características da força de trabalho relacionados a distintas disciplinas como a macro e a microeconomia, a economia política, a sociologia do trabalho e a sociologia industrial, entre outras.

É ainda importante sublinhar as contribuições teóricas da sociologia das profissões para a análise sobre as reconfigurações do mercado de trabalho em saúde. Se a força de trabalho em saúde é influenciada pela dinâmica dos mercados de trabalho, dadas a sua composição e a sua especificidade, ela também é influenciada por sua composição multiprofissional e pelas características das várias profissões que a compõem, como demonstra a sociologia das profissões (Peduzzi e Schraiber, 2008).

A temática inicial dessa abordagem estava voltada para os elementos constitutivos do que se considera profissão ou trabalho profissional. Ora os autores procuravam apontar os atributos do que consideravam profissões, ora o destaque era para o'processo de profissionalização' (Bosi, 1996) - o que permitiu aprofundar a compreensão de lógicas e dinâmicas dos mercados profissionais, como por exemplo a dos médicos. ${ }^{2}$

O processo de profissionalização passa a ser entendido como um conjunto de ações por meio das quais uma ocupação ou semiprofissão busca elevar seu prestígio, bem como seu poder e seus ganhos. A luta pela conquista do status profissional se dá pelo monopólio de determinadas competências; pela organização para a garantia de jurisdição mais ou menos exclusiva; pelo grau de autonomia profissional e, consequentemente, pela garantia de um espaço no mercado de trabalho (Machado, 1995).

O conjunto das teorias centradas na análise do mercado permite acompanhar o cenário geral de mudanças e seus impactos em: relações de trabalho; mobilidade social dos trabalhadores; sistemas de contratação e remuneração; rotatividade e qualidade dos postos de trabalho; processo migratório; dife- 
renças de gênero e etnia; níveis de organização e qualificação da força de trabalho; risco social; e exclusão/desemprego, que se transformam em temáticas fundamentais.

Para esses estudos são importantes as bases de dados oficiais, censos e pesquisas domiciliares, que podem ser utilizadas para medir e caracterizar o mercado de trabalho (Oliveira e Machado, 2010; Oliveira, 2010). Dados sobre a demanda por trabalhadores permitem acompanhar características como qualificação exigida, benefícios ofertados, tipos de condições laborais e comparação de perfis e estruturas da oferta de trabalho (Gómez, 2000).

Convém, entretanto, considerar as diferenciações metodológicas em relação a bases de dados disponíveis, sobretudo para comparação entre realidades nacionais ou regionais em um mesmo país, entre diferentes áreas da economia ou entre setores público ou privado, por exemplo (Nogueira, 2002). Possíveis mudanças nos procedimentos de coleta de informações são observadas, principalmente no momento de desenho de séries históricas. O índice de desemprego, para exemplificar, é por muitas vezes ajustado aos contextos políticos em diferentes países.

Destaca-se, ainda, que a diversidade de estudos publicados sobre o mercado de trabalho também considera a especificidade das experiências de cada país ou região. Segundo Ferreira (1999), os enfoques variam segundo fatores como: a industrialização tardia ou não; a posição do país/região quanto à subcontratação internacional/nacional; o peso dos empregos nos setores tradicionais; o grau de dependência tecnológica e os padrões de qualificação da força de trabalho.

Os estudos realizados na perspectiva do mercado se aproximam dos fatores de ordem macro, de caráter estrutural, segundo o modelo de desenvolvimento econômico adotado. Na área de saúde, tais estudos tomam como objeto de análise o conjunto dos trabalhadores ocupados no setor, as diversas áreas profissionais incorporadas aos serviços, seus perfis profissionais, ao mesmo tempo que analisam trabalhadores como parte considerável e crescente do total da força de trabalho nos diversos espaços de produção (Nogueira, 1992; Dedecca e Trovão, 2013). O mercado de trabalho é analisado dentro do complexo produtivo da saúde, com destaque para o seu papel na geração de empregos e renda.

\section{Perspectiva do Estado: o trabalhador como elo entre a sociedade e o Estado}

O movimento de flexibilização na utilização do capital e do trabalho deixa de pertencer somente ao espaço do mercado, alcançando também o setor público. O papel do Estado e dos governos e suas formas de gestão ganham visibilidade, emedidas restritivas passama comporumaagenda de reformas em grande parte dos países, onde o modelo de incorporar e gerir o trabalho têm lugar de destaque (Kaufman, 1998). 
No campo teórico, a relação Estado e sociedade, principal preocupação da ciência política, passa por revisões, e novos pressupostos são adotados para o estudo das políticas públicas. Esta temática ganha status de campo de estudo multidisciplinar, não só nos países desenvolvidos como também no Brasil, mais recentemente, por meio de fóruns e grupos temáticos em diferentes associações científicas.

Durante as décadas de 1950 e 1960, a ciência política tinha como principal fonte de análises os modelos explicativos do pluralismo e do marxismo. O modelo pluralista que orientou muitos trabalhos empíricos sobre as políticas públicas é caracterizado por conceber a distribuição de poder, em países democráticos, como um fenômeno mais ou menos constante, composto de vários centros de poder e nenhum deles soberano (Skocpol, 2012; Marques, 1997; Souza, 2003; Rocha, 2005).

O conceito de 'grupo de interesse' ou 'grupo de pressão' e suas formas de estabelecer coalizões em busca de determinados objetivos são adotados como principais instrumentos analíticos. Valorizam não mais as fontes de poder, mas o seu exercício (Rocha, 2005). Preocupam-se em: identificar e selecionar as decisões políticas-chaves e não rotineiras; identificar pessoas ou grupos ativos nas decisões; observar seu comportamento e analisar os resultados de sua ação (Bachrah e Baratz, 2011).

Outro modelo muito difundido, principalmente entre os anos 1970 e 1980, foi o marxista. De forma pouco aprofundada, pode-se dizer que a análise marxista para a relação Estado e sociedade parte da relação entre economia, classes sociais e Estado. As políticas de Estado, este com autonomia relativa, são resultados dos interesses da classe que domina a sociedade. A análise das políticas públicas, portanto, passa pelo estudo de influência da classe dominante na definição das ações do Estado (Marques, 1997). Esse modelo influenciou um conjunto importante de estudos sobre o trabalho em saúde, entre os quais se destacam, no Brasil, os trabalhos de Mendes Gonçalves (1979), um dos teóricos que participaram da construção do campo da saúde coletiva brasileira nos anos 1970-1990.

No entanto, mesmo que em oposição quanto a seus pressupostos, esses diferentes modelos de análise convergem quanto ao foco: a ação estatal é sempre resposta a estímulos vindos da sociedade, a análise é society-centered, a ênfase analítica é na dinâmica da sociedade e no poder que seus diferentes atores políticos têm sobre os Estados (Rocha, 2005; Viana e Baptista, 2009).

Em meados dos anos 1980, contrapondo-se aos modelos pluralista e marxista, outro modelo de análise, o neoinstitucionalista, passa a se sobressair no campo de estudo sobre a relação Estado e sociedade. Referência desse movimento, o trabalho de Evans, Rueschemeyer e Skocpol (1985) parte de críticas às abordagens anteriores, recolocando o Estado como foco privilegiado de análise, inaugurando, segundo Rocha (2005), a primeira fase de análises do neoinstitucionalismo, denominada de state-centered. 
Propõe-se uma reorientação teórica cuja principal premissa é a da autonomia do Estado. $O$ destaque dessa nova abordagem é o papel primordial das instituições e dos atores estatais na esfera da política, com a sociedade civil permanentemente influenciada pelo Estado. Nessa fase de análises sobre a relação entre Estado e sociedade, as ações do Estado, segundo Skocpol (2012), teriam como objetivos a manutenção de sua autoridade, poder político e ampliação de sua capacidade de ação, buscando reproduzir o controle de suas instituições sobre a sociedade. Para essa abordagem, decisões públicas seriam resultado, principalmente, dos interesses e das percepções que a burocracia tem da realidade.

Ainda citando Skocpol (2012), um conjunto de estudos comparados sobre as estruturas estatais em sociedades democráticas fortalece as teses de que: 0 Estado é um conceito variável; há diferenças institucionais e culturais entre países; a estrutura e a forma de atuação do Estado estimulam a proliferação de grupos de interesse que competem entre si; Estados são entendidos como organizações por meio das quais funcionários estatais buscam diferentes objetivos, implementando-os de forma mais ou menos eficiente de acordo com recursos disponíveis, em determinado cenário social.

Após críticas à ideia de autonomia do Estado como um fenômeno generalizável, a abordagem neoinstitucionalista amplia o seu escopo de análise para uma nova perspectiva denominada por Skocpol de polity-centered analysis (Skocpol, 1995, apud Rocha, 2005). Tal perspectiva busca equilibrar o papel do Estado e da sociedade nos estudos de caso, ampliando também sua temática, que passa a incluir: instituições governamentais, regras eleitorais, partidos políticos e políticas anteriores como fatores condicionantes da sociedade civil (Rocha, 2005).

Ao discutir o neoinstitucionalismo como uma possível estratégia metodológica para as políticas de saúde, Lima, Machado e Gerassi (2011) chamam a atenção para o fato de que as respostas para as questões de investigação estariam nas estruturas intermediárias - as instituições - que fazem a mediação entre Estado e sociedade, entre estruturas econômicas e comportamentos de indivíduos e grupos, modelando processos políticos e sociais nos diferentes países.

A abordagem analítica do neoinstitucionalismo valoriza ainda o fato de cada Estado ter uma capacidade e uma estrutura institucionais próprias, e o poder político dos diferentes grupos depender, em grande medida, desses elementos. Por sua vez, os instrumentos de políticas estatais são criações deliberadas de acordo com a história de cada nação ou região, isto é, as políticas estatais são estruturadas no espaço e no tempo.

Para os estudiosos dessa perspectiva, não é possível estabelecer grandes postulados definitivos ou teorias gerais, mas apenas teorias de médio alcance, baseadas em afirmações provisórias a serem testadas e alteradas de acordo com a observação de contextos específicos e sua história (Marques, 1997; Fernandes, 2007; Lima, Machado e Gerassi, 2011). 
A perspectiva neoinstitucionalista ressalta a importância das instituições, conceito-chave para o entendimento dos processos sociais e políticos, que passa a compor o instrumental teórico-metodológico do conjunto de pesquisas. A instituição pode ser definida de forma global "como os procedimentos, protocolos, normas e convenções oficiais e oficiosas inerentes à estrutura organizacional da comunidade política ou da economia política" (Hall e Taylor, 2003, p. 196); ou mesmo "sistemas de regras sociais estabelecidas e predominantes, que estruturam as interações sociais, Linguagem, dinheiro, Leis, sistemas de pesos e medidas, empresas e outras organizações" (Hodgson, 2006, p. 2).

Embora com pressupostos em comum, o neoinstitucionalismo comporta distintas vertentes. Os autores desse campo identificam as primeiras versões: o institucionalismo da escolha racional, o sociológico e o histórico, e duas versões mais recentes: o institucionalismo construtivista e o institucionalismo de redes (Lima, Machado e Gerassi, 2011).

Cada uma dessas vertentes trabalha com pressupostos teóricos e instrumentos analíticos próprios que podem auxiliar na análise de questões centrais dos processos que envolvem a relação do Estado com a sociedade e suas contribuições para a análise da política de saúde, o que tem sido ressaltado por diversos autores como Hochman, Arretche e Marques (2007), Hochman (2013), Viana e Baptista (2009), Lima, Machado e Gerassi (2011). Mesmo com divergências metodológicas, os autores valorizam a interação entre as versões das análises neoinstitucionalistas, que não seriam excludentes ou antitéticas, mas complementares, tendo em vista que cada uma busca elucidar o papel desempenhado pelas instituições na determinação dos resultados sociais.

De forma resumida, essas versões podem ser caracterizadas chamando-se a atenção para o fato de que cada uma delas prioriza uma dimensão da relação Estado e sociedade, determinando uma seleção diferenciada de quantas e quais instituições influenciam mais no comportamento dos indivíduos, que temas e perguntas serão feitas, que teorias serão buscadas e que conceitos e variáveis serão privilegiados.

A primeira vertente, o institucionalismo da escolha racional, tem origem no estudo do comportamento no interior do Congresso dos Estados Unidos da América. O centro da pesquisa é o comportamento dos indivíduos, que é marcado por cálculos estratégicos, mais do que por valores. Esse enfoque considera as instituições como 'regras do jogo', ora entendidas como fatores exógenos que restringem o comportamento dos atores, ora podendo ser modificadas por um decisive player. Exemplos de instituições para essa abordagem seriam: o poder de agenda, a estrutura partidária das comissões, os poderes de decisão das comissões, as restrições, as possibilidades de encaminhamento de emendas e peças legislativas por parte de legisladores individuais, entre outros (Hall e Taylor, 2003). 
O institucionalismo histórico, que tem origem nos estudos de política comparada entre países, especialmente os estudos de economia política comparada (Thelen e Steinmo, 1992), também chama a atenção para o papel das instituições na vida política. Entretanto, não as considera como o único fator influente, buscando situá-las em uma cadeia causal que se liga a outros fatores, como os interesses, os atores e a distribuição de poderes entre eles. Mais importante do que as características formais das instituições estatais e sociais é como as interações políticas modelam objetivos, prioridades e decisões (Thelen e Steinmo, 1992). Essa vertente dedica maior atenção aos contextos e configurações históricos na análise das instituições políticas. $O$ conceito-chave para essa versão é a dependência da trajetória (path dependence), que explicaria como escolhas políticas do presente podem ser limitadas por decisões ou eventos passados.

O institucionalismo sociológico vincula-se à teoria das organizações (década de 1970), preocupa-se com as vias pelas quais as instituições influenciam preferências e identidades subjacentes dos atores. As instituições são definidas de maneira mais ampla, compreendidas como sinônimo de cultura, como uma rede de hábitos, símbolos e cenários que fornecem modelos de comportamento, difundindo modelos institucionais (Hall e Taylor, 2003).

Em uma vertente mais recente, institucionalismo construtivista, a variável conhecimento assume lugar de destaque na definição de resultados políticos. Por se concentrar na análise de como as ideias políticas são produzidas, disseminadas e reproduzidas, essa versão tem como objetivo explicar, por exemplo, por que alguns indivíduos adotam posições que contradizem seus interesses materiais aparentes, ou como podem ser formadas coligações que reúnam atores sociais com interesses políticos concorrentes (Béland e Cox, 2011).

Também recente, a vertente do institucionalismo de redes reconhece as redes como instituições, por estas representarem padrões estáveis ou concorrentes de interação e trocas entre indivíduos, grupos e organizações, sendo assim variável que afeta a distribuição de poder e a construção de identidades e interesses que caracterizam essas interações (Lima, Machado e Gerassi, 2011). Para essa abordagem, o desenvolvimento das políticas do Estado envolve a interação em uma policy network entre atores públicos e privados que, com base em suas posições, intercambiam recursos em ambientes institucionais considerando padrões de relações preexistentes (Romano 2007, apud Castro, 2013).

Em um cenário de flexibilização e mudanças do modelo de gestão do Estado, tanto nacional como internacionalmente, o neoinstitucionalismo, em suas diferentes vertentes, tem se apresentado como uma opção metodológica cada vez mais presente na discussão do trabalho no setor público de saúde, na medida em que toma como categoria central de análise as instituições e os atores estatais na esfera da política. 
Entre os trabalhos que utilizam esse referencial para discutir o trabalho em saúde no setor público estão os estudos de Costa e Lamarca (2013), que associam a condição da força de trabalho do governo central brasileiro às mudanças na coalizão governamental recorrendo à vertente da escolha racional; e o trabalho de Dias, Lima e Teixeira (2013), que aborda a trajetória da Política Nacional de Reorientação da Formação Profissional em Saúde em uma vertente histórica.

\section{Perspectiva da atividade: o trabalho como prática social}

Além das mudanças nos padrões de produção e das novas demandas para os Estados, a flexibilização chega ao plano da atividade laboral (a chamada flexibilidade funcional), que se relaciona: aos conhecimentos técnicos e demais competências dos trabalhadores e sua capacidade deadaptação a uma série de tarefas; ao domínio de diversos segmentos de um mesmo processo produtivo; e a competências sociais, comunicativas e políticas que passama ser exigidas (Lagos, 1994).

Um conjunto de disciplinas e abordagens constitui-se a partir dos estudos da psicologia social do trabalho e da ergonomia, priorizando as lacunas entre o que é prescrito e o que é a prática real do sujeito em atividade. Tais abordagens contemplam a dinâmica subjetiva envolvida no trabalhar, bem como a luta contra o sofrimento, as estratégias de defesa, as regras de ofício, os impedimentos da ação, as renormatizações e a saúde do trabalhador (Leão, 2012).

Leão (2012), que tem sua origem acadêmica na psicologia social, ressalta que essas vertentes não partem de um mesmo referencial teórico, não se traduzindo, portanto, em uma abordagem homogênea. As principais abordagens são por ele destacadas: a psicodinâmica do trabalho (Dejours, Abdoucheli e Jayet, 1994; Molinier, 2004), a psicossociologia clínica (Henriquez, 2005; Gaulejac, 2007), a clínica da atividade (Clot, 2007) e a ergologia (Schwartz, 2002). Aponta ainda tanto aproximações quanto afastamentos entre elas: a psicodinâmica do trabalho, por exemplo, se apoia nas abordagens compreensivas e na filosofia de Jürgen Habermas; a psicossociologia clínica se baseia na psicanálise e na abordagem sociotécnica inglesa, enquanto a clínica da atividade está ancorada nos estudos de Mikhail Bakhtin, na filosofia de Baruch Espinosa e na psicologia de Lev Vygotsky (Leão, 2012).

A ergologia, embora não se configure como uma disciplina (Schwartz, 2002), e sim uma perspectiva de análise sobre o trabalho, apoia-se principalmente na filosofia de Georges Canguilhem (2001) e tem contribuído para o estudo da atividade em diferentes países e no Brasil.

Diante das mudanças trazidas pela flexibilidade funcional e com a preocupação de repensar o regime de produção de conhecimento sobre o trabalho, o filósofo Yves Schwartz, no final da década de 1970, inicia suas reflexões a 
partir da dificuldade de diálogo entre o universo pedagógico das escolas e a formação profissional. Sua hipótese inicial era a de que existiam no trabalho formas de cultura, de acumulação de patrimônios (da ordem dos saberes e valores), desarticuladas tanto da formação profissional quanto da formação geral. Assim, para o entendimento do mundo do trabalho, novos elementos passam a importar, "saberes, os laços coletivos, os valores, as contradições, as lutas, os sentimentos de insuficiências" (Schwartz, 2000, p. 39), presentes no cotidiano do trabalho e que não poderiam ser desconsiderados. Desse modo, para o autor, novas formas de compreender o trabalho se faziam necessárias, já que a visão tradicional, taylorista, não mais atenderia às necessidades dos indivíduos que o realizam.

Esse desafio impôs o encontro entre pesquisadores de diversas disciplinas e trabalhadores, com o objetivo de buscar novos referenciais teóricos capazes de promover essa integração e envolvê-los numa lógica transdisciplinar de produção de conhecimentos sobre a atividade. Tal processo foi efetivado em encontros acadêmicos com ativa participação dos trabalhadores e que aconteceram tanto nos espaços acadêmicos na Universidade de Provence, na França, quanto nos espaços das empresas e de sindicatos. Essa atividade esteve apoiada no conceito de 'comunidade científica ampliada', segundo o qual se considera a aprendizagem mútua entre os envolvidos, buscando uma confrontação entre os saberes produzidos no e pelo trabalho com os saberes produzidos nos diversos campos científicos.

Na ergologia,'método de investigação pluridisciplinar', o foco é o estudo da atividade humana na realização do trabalho, o que significa aceitar que o normatizado, prescrito ou mesmo imposto pela organização não é executado em sua plenitude, uma vez que o sujeito o executa respeitando sua singularidade e capacidade reflexiva (Schwartz, Duc e Durrive, 2010).

Para os autores da ergologia, o visível são objetos, técnicas, tradições, o codificado, mas o que é prioridade é o invisível, ou seja, a ação humana, tudo aquilo que faz viver as técnicas num dado momento. Assim, o espaço onde acontece o processo de trabalho não deve ser entendido como um lugar onde se realiza algo, ou um ambiente de trabalho, mas um espaço das situações vividas por aqueles que realizam as atividades laborais. Dessa forma, uma atividade de trabalho é sempre entendida como o lugar de reapreciação e julgamentos sobre os procedimentos e os processos de trabalho, que estabelece um vaivém entre o micro do trabalho e o macro da vida social (Schwartz, 2011).

A ergologia propõe trazer para o centro da pesquisa a experiência dos trabalhadores, articulando os saberes formais (acadêmicos) e os saberes informais (experiência dos trabalhadores) por meio de um 'dispositivo dinâmico dos três polos'. O primeiro polo é aquele dos saberes conceituais das disciplinas; o segundo é o dos saberes investidos no exercício do trabalho e na experiência; o terceiro significa uma postura ética e epistemológica, presente 
nos projetos em comum que acordam entre si os outros dois polos, implicando que todos os que participam (trabalhadores e pesquisadores) tornam-se coautores do conhecimento produzido (Vieira, Barros e Lima, 2007; Oliveira, 2007). Tal perspectiva busca, assim, encontrar em cada situação no cotidiano do trabalho não a simples execução de uma instrução e de procedimentos, mas antes a realização parcialmente original, uma 'renormatização' (Schwartz, Duc e Durrive, 2010).

Para falar do trabalhador, a ergologia utiliza o conceito de corpo-si, o centro das dramáticas laborais, o árbitro no mais íntimo da atividade e que não é um 'sujeito' delimitado, mas um ator que resiste às tentativas de ser objetivado (Schwartz, Duc e Durrive, 2010). Conforme esses autores, o trabalhador faz, de modo singular, a gestão de suas atividades, em que essa gestão passa por economias do corpo, por sinalizações sensoriais e visuais, pela postura, pelo neurofisiológico e pela inconsciência do próprio corpo. Assim, a entidade que atua não é inteiramente biológica, nem inteiramente consciente ou cultural; a atividade não é considerada apenas como uma ação, mas também convocação permanente do corpo-si (Schwartz, 2000). É o corpo-si que experiencia as pressões econômicas e políticas, especialmente as geradas pelas mudanças tecnológicas e institucionais (Oliveira, 2007).

É a partir dessas questões que se aponta para o espaço das atividades como o espaço das dramáticas de uso de si, dos debates de normas, das gestões do e no trabalho (Schwartz, 2002). Segundo Holz (2012), a ideia de corpo-si revela a insuficiência do termo 'recurso humano', passível de utilização gerencial. Para os autores da ergologia, o que está em jogo é a necessidade de mobilização das capacidades e dos recursos dos trabalhadores, deixando de ser mera execução das tarefas, mas o uso de si. Se a ênfase é dada aos debates sobre normas e valores presentes nas situações do trabalho, no entanto, também se reconhece que esse espaço é atravessado por pressões externas, do mercado e do político.

Vale sublinhar que esses dois polos, o do mercado e o do Estado, não são territórios perfeitamente delimitados ou independentes, mas constituem-se em uma gama de situações intermediárias que funcionam como polos imantados que ora se atraem, ora se repelem (Schwartz, Duc e Durrive, 2010).

Schwartz, Duc e Durrive (2010) propõem um espaço/esquema tripolar para a análise das sociedades democráticas que contemple a dialética do geral e do singular, considerando-se que em toda atividade de trabalho há uma dimensão micro e uma dimensão macro; é também onde são feitas escolhas, debates de normas, encontros de valores, enfim, o local onde o processo histórico é construído. Essa perspectiva de análise sobre o trabalho afirma que a transformação dos mundos do trabalho é também operada no cotidiano, pelos seus protagonistas em atividade, e em diálogo com transformações mais visíveis e globais (Schwartz, Duc e Durrive, 2010). 
Os três polos não podem ser considerados objetos de mutações bruscas em que as mudanças são operadas a um só tempo. Esses polos funcionam em 'temporalidades-valor ou tempo-valor' heterogêneas entre si. O polo do mercado tem uma temporalidade cada vez mais volátil, sobretudo com o desenvolvimento das novas formas de comunicação, internet, processos de especulação etc. No plano político, as mudanças se manifestam em outro ritmo, mediante crises, mudanças de maiorias parlamentares, em respostas a demandas dos outros polos etc. Mas as inflexões históricas podem ser em boa medida compreendidas pelas mudanças que se dão no polo das gestões, da atividade, em que pouco a pouco as contradições são experimentadas exigindo mudanças.

Como estratégias metodológicas de aproximação das situações de trabaIho, recorre-se ao dispositivo denominado comunidade ampliada de pesquisa (CAP), na tentativa de colaborar para a sinergia entre os polos que configuram a perspectiva ergológica, com o objetivo de estimular a parceria entre pesquisadores e pesquisadores profissionais (como são chamados aqueles que exercem o trabalho em análise e suas representações sindicais). Por meio de método de alternância de estratégias, com realização de cursos/exercícios de análise pelos trabalhadores e 'encontros sobre o trabalho', que combinam formação, pesquisa e intervenção, constrói-se um 'espaço dialógico particular de confronto de saberes e experiências', fazendo circular na CAP a análise do trabalho individual e coletivo, o que permite recriar a atividade realizada.

A abordagem ergológica vem ganhando espaço acadêmico em diferentes centros de pesquisa no país, os quais, segundo dados do Coletivo Ergologia ${ }^{3}$, conformam hoje um conjunto importante de instituições universitárias distribuídas em todas as regiões brasileiras.

No campo da saúde, mais especificamente nos estudos sobre saúde do trabalhador e da psicologia social, a perspectiva ergológica vem sendo utilizada para discutir as transformações do mundo do trabalho com foco na reflexão e análise das atividades humanas.

\section{Considerações finais}

A opção metodológica em fazer uma revisão narrativa com base nas diferentesperspectivasdeanálisedotrabalhoemsaúdepromoveumaampliaçãodas possibilidades de olhar o campo do trabalho em saúde, a escolha de temase caminhos para a investigação. Acreditamos que análises articulando várias perspectivas teóricas tendem a ser mais completas. Segundo Doise (2002, p. 28), "análises em vários níveis conduzem a uma melhor descrição de um processo conceitualizadoem um dos níveis, precisando, prioritariamente, as condições de sua atualização, a partir dos outros níveis de análise".

No entanto, cabe sublinhar a necessidade de se limitar e recortar os objetos de estudo, selecionar as abordagens utilizadas, para escolhas mais precisas sobre a temática, os trajetos e os conceitos que serão utilizados. O mais impor- 
tante é o reconhecimento de que as questões do trabalho em saúde pertencem a uma agenda de pesquisa tripolar, mesmo que não seja possível contemplar a um só tempo todas as perspectivas e abordagens aqui identificadas.

Os fatores enunciados na primeira perspectiva são de natureza estrutural e decorrem: do tipo de sistema econômico; dos modelos de desenvolvimento adotados; dos valores e princípios sociais prevalentes; dos paradigmas culturais e das visões do mundo subjacentes nas políticas, podendo conduzir a maior ou menor grau de precarização do trabalho e de proteção social, entre outros fatores.

Os fatores de ordem 'meso', embora possam ser de natureza tanto estrutural como conjuntural, são mais localizados, reportando-se a fatores diversos como as políticas estatais; os modos de funcionamento dos organismos da administração central; os modos de organização e controle da sociedade civil; o funcionamento das redes sociais e o modo como elas se relacionam com as questões apresentadas para o trabalho em saúde.

Tanto os fatores de ordem macro como os de ordem 'meso' reportam-se às oportunidades (políticas, medidas, recursos) disponibilizadas ou negadas pela sociedade/Estado/instituições.

As análises a partir do conceito de atividade partem do pressuposto teórico de que as dimensões políticas e econômicas configuram o trabalho como uma prática social. Ao convocar os saberes que emergem dos trabalhadores, identificam a atividade como um lugar permanente de microescolhas, de debate sobre normas e valores, possibilitando que os trabalhadores formalizem suas experiências (Oliveira, 2007).

Acreditamos que o debate incluindo diferentes perspectivas sobre um mesmo objeto pode promover um diálogo entre as abordagens trazendo contribuições aos estudos realizados. Tendo em vista que cada uma revela aspectos importantes dos impactos das mudanças em relação ao trabalho, amplia-se, por conseguinte, a agenda de problemas e questões para a análise sobre o trabalho em saúde.

É certo que a forma como o trabalho é flexibilizado está condicionada pelos fatores estruturantes enunciados e políticas tomadas em nível macro. No entanto, a ausência, a não concretização ou a inadequação das medidas adotadas nesse nível não significam que se devam subestimar medidas tomadas no nível 'meso' ou micro, que podem fazer a diferença na qualidade do trabalho em geral e na do trabalho em saúde em particular.

\section{Colaboradores}

Marcia Teixeira trabalhou na concepção, pesquisa e redação final; Maria Inês Carsalade Martins, Isabel Cristina Silva Arruda Lamarca e Simone Oliveira, na revisão crítica e redação final. 


\section{Financiamento}

Este suplemento “Educação e Trabalho em Saúde: diálogos e experiências no Brasil e em Portugal" foi realizado com apoio da Coordenação de Aperfeiçoamento de Pessoal de Nível Superior (Capes) - Código de Financiamento 001; e do Departamento de Pesquisa em História das Ciências e da Saúde da Casa de Oswaldo Cruz (Depes/COC/Fiocruz, 6151000000). Todos os autores declaram que não há conflito de interesses.

\section{ENFOQUE DEL TRABAJO EN EL SECTOR PÚBLICO DE SALUD: UNA REVISIÓN NARRATIVA DE LA LITERATURA}

Resumen Este artículo es una revisión narrativa de literatura identificando diferentes enfoques teóricos que se han utilizado en la discusión sobre el trabajo en salud. Nuestro objetivo es actualizar el conocimiento sobre esta temática, mapeando las diferentes estrategias metodológicas. La bibliografía fue organizada según tres perspectivas de análisis: mercado - los sujetos del trabajo vistos como fuerza productiva, Estado - los sujetos del trabajo entendidos como vínculo entre Estado y sociedad, y actividad - la dimensión subjetiva del trabajo. Esta estrategia permitió una visión integrada del campo, señalando los diferentes, pero complementarios caminos metodológicos para el análisis del trabajo en el sector público de salud.

Palabras clave trabajo en salud; mercado de trabajo en salud; proceso de trabajo en salud; actividad en salud, política de gestión del trabajo en salud.

\footnotetext{
Notas

${ }^{1}$ Teoria que surgiu na França - Universidade de Provence - na década de 1970, orientada para o estudo das transformações do trabalho que estavam em curso. Sua abordagem pluridisciplinar e pluriprofissional estuda as situações de trabalho, convocando diversas disciplinas como a economia, a ergonomia, a psicologia, a linguística, a filosofia, o direito e a sociologia para criar um dispositivo de análise das situações de trabalho (Oliveira, 2007).

${ }^{2}$ Dentre os teóricos representantes das diferentes correntes presentes nesse campo, destacam-se autores como Moore (1970), Wilensky (1970), Goode (1969), Larson (1977) e Freidson (1978). No Brasil, cabe destacar alguns estudos utilizando esse referencial, como as contribuições de Marinho (1986), Coelho (1995), Machado (1991) e Schraiber e Peduzzi (1993).
}

${ }_{3}^{3}$ Disponível em: @ColetivoErgologia no Facebook. Acesso em: 10/09/2019. 


\section{Referências}

ANTUNES, Ricardo. Adeus ao trabalho? Ensaio sobre as metamorfoses e a centralidade no mundo do trabalho. 3ed. São Paulo: Cortez; Campinas, SP: Editora da Universidade Estadual de Campinas, 1995.

BACHRACH, Peter; BARATZ, Morton S. Duas faces do poder. Revista Sociologia e Política, Curitiba, v. 19, n. 40, p. 149-157, out. 2011.

BÉLAND, Daniel; COX, Robert H. Ideas and politics in Social Science research. New York: Oxford University Press, 2011.

BELL, Daniel. O Advento da Sociedade Pós-industrial. São Paulo: Cultrix, 1973.

BERTERO, José F. Sobre a sociedade pós-industrial. Comunicação apresentada no IV Colóquio Marx e Engels em Campinas, SP, 2005. Disponível em: <http://www.unicamp. br/cemarx/ANAIS\%20IV\%20COLOQUIO/ comunica\%E7\%F5es/GT3/gt3m2c4.pdf>. Acesso em: 25-set- 2013.

BOSI, Maria L. M. Profissões e profissionalização: o debate teórico. In: BOSI, Maria L. M. Profissionalização e conhecimento: a nutrição em questão. São Paulo: Hucitec, 1996. p. 35-56.

CANGUILHEM, Georges. Meio e Normas do Homem no Trabalho. Tradução de Conceição Vigneron. Proposições, Campinas, v. 12, p. 109121,jul./nov. 2001. Disponível em: https://www. fe.unicamp.br/pf-fe/publicacao/2113/3536-artigos-canguilhemg.pdf. Acesso em: 25-out- 2014.

CASTEL, Robert. Metamorfoses da questão social. Petrópolis: Vozes, 1998.

CASTRO, Luiza M. A. Do neoinstitucionalismo tradicional às redes: as mudanças colocadas a partir do modelo de governança. In: Encontro da ASSOCIAÇÃO NACIONAL DE PÓS-GRADUAÇÃO E PESQUISA EM ADMINISTRAÇÃO, 37, Rio de Janeiro, set. 2013. Disponível em http://www.anpad.org.br/admin/ pdf/2013_EnANPAD_APB1931.pdf Acesso em nov de 2017.
COELHO, Edmundo C. Físicos, sectários e Charlatães: a medicina em perspectiva histórico-comparada. In: Profissões de Saúde: uma abordagem sociológica. MACHADO, Maria H.V (org.). Rio de Janeiro: Editora Fiocruz, 1995. p. 35-62.

CLOT, Yves. A função psicológica do trabalho. Petrópolis: Vozes, 2007.

CORIAT, Benjamin. Pensar pelo avesso: o modelo japonês de trabalho e organização. Tradução Emerson S. da Silva. Rio de Janeiro: Revan, UFRJ, 1994.

COSTA, Nilson R.; LAMARCA, Isabel. Os governos $\mathrm{FHC}$ e Lula e a política para a força de trabalho civil do governo central brasileiro. Ciência \& Saúde Coletiva, Rio de Janeiro, v. 18, n. 6, p. 1.601-1.612, jun. 2013.

DEDECCA, Cláudio S. Racionalização econômica e heterogeneidade nas relações e nos mercados de trabalho no capitalismo avançado. In: OLIVEIRA, Carlos A. B.; MATTOSO, Jorge E. L. (orgs.). Crise e trabalho no Brasil: modernidade ou volta ao passado? São Paulo: Scritta, p. 55-87, 1996.

DEDECCA, Cláudio S.; TROVÃO, Cassiano J. B. M. A força de trabalho no complexo da saúde: vantagens e desafios. Ciência \& Saúde Coletiva, Rio de Janeiro, v. 18, n. 6, p. 1.5551.568, jun. 2013.

DEJOURS, Cristophe; ABDOUCHELI, Elisabeth A.; JAYET, Christian. Psicodinâmica do trabalho: contribuições da escola dejouriana à análise da relação prazer, sofrimento e trabalho. São Paulo: Atlas, 1994.

DIAS, Henrique S.; LIMA, Luciana D.; TEIXEIRA, Marcia. Trajetória da Política Nacional de Reorientação da Formação Profissional em Saúde no SUS. Ciência \& Saúde Coletiva, Rio de Janeiro, v. 18, n. 6, p. 1.613-1.624, jun. 2013.

DOISE, Willem. Da psicologia social à psicologia societal. Psicologia:Teoria e Pesquisa, Brasília, v. 18, n. 1, p. 27-35, jan.-abr. 2002. 
DONNANGELO, Maria C. F. Medicina e sociedade: o médico e seu mercado de trabalho. São Paulo: Pioneira, 1975.

ENRIQUEZ, Eugene. Psicanálise e ciências sociais. Revista Ágora, Rio Janeiro, v.8, n.2, p. 153-174, 2005.

EVANS, Peter B., RUESCHEMEYER, Dietrich, SKOCPOL, Theda. Bringing the State Back In. Cambridge: Cambridge University Press, 1985.

FERNANDES, Antônio S. A. Path dependency e os estudos históricos comparados. In: SIMPÓSIO NACIONAL DE HISTÓRIA, 24, 2007, São Leopoldo, RS. ASSOCIAÇÃO NACIONAL DOS PROFESSORES UNIVERSITÁRIOS DE HISTÓRIA, 15 a 20 de julho de 2007.

FERREIRA, António C.; COSTA, Hermes A. Para uma sociologia das relações laborais em Portugal. Revista Crítica de Ciências Sociais, Coimbra, n. 52/53, p. 141- 171, nov. 1998fev. 1999.

FREIDSON, Eliot. La Profesión Médica: um studio del la sociologia del conocimiento aplicado, Barcelona, Edições Península, 1978.

GAULEJAC, V. Gestão como doença social. Ideologia, poder gerencialista e fragmentação social. São Paulo: Ideias \& Letras, 2007.

GOODE, Willian J. The Theoretical Limits of Professionalization. In: The Semi-professions and Their Organization. ETZIONI, Amitai (ed.). New York: New York Press, 1969. p. 266-313.

GÓMEZ, Marcelo. Algunas características de la demanda laboral durante el Plan de Convertibilidad en la Argentina. In: CONGRESSO LATINO AMERICANO DE SOCIOLOGIA DO TRABALHO, 3, Buenos Aires, 17-20 maio 2000.

HALL, Peter A.; TAYLOR, Rosemary C. R. As três versões do neoinstitucionalismo. Lua Nova, Rio de Janeiro, n. 58, p. 193-223, 2003.

HOCHMAN, Gilberto; ARRETCHE, Marta; MARQUES, Eduardo (orgs.). Políticas públicas no Brasil. Rio de Janeiro: Editora Fiocruz, 2007.
HOCHMAN, Gilberto. História e políticas públicas. In: MARQUES, Eduardo; FARIA, Carlos A. P. F. (orgs.). A política pública como campo multidisciplinar. São Paulo: Editora Unesp; Rio de Janeiro: Editora Fiocruz, 2013. p. 225-242.

HODGSON, Geoffrey. What are institutions? Journal of Economic Issues, v. 15, n. 1, p. 1-25, mar. 2006. Disponível em: <http://www.geoffrey-hodgson.info/user/bin/whatareinstitutions. pdf> Acesso em: abril-2017.

HOLZ, Edvalter B. Cinco apontamentos ergológicos sobre o novo RH. Gestão \& Sociedade, Belford Roxo, v. 1, n. 2, p. 1-16, ago.-dez. 2012.

KAUFMAN, Robert. A política da Reforma do Estado: um exame de abordagens teóricas. Revista do Serviço Público, Brasília, v. 49 n. 1, p. 43-69, 1998.

KOVÁCS, Ilona. Trabalho, emprego e organizações na era da globalização: controvérsias. In: RIBEIRO, Fernando B.; SILVA, Manuel C.; MARQUES, Ana P. P. (orgs.). Trabalho, técnicas e mundo: perspectivas e debates. Vila Nova de Famalicão: Editora Humus, 2012. p. 39-59.

LAGOS, Ricardo A. Qué se entiende por flexibilidad del mercado de trabajo. Revista de la Cepal, Santiago, n. 54, p. 81-95, dez. 1994.

LARSON, Magali. The rise of professionalism: a sociological analysis. Los Angeles, University of California Press, 1977.

LEÃO, Luís H. C. Psicologia do trabalho: aspectos históricos, abordagens e desafios atuais. Revista Ecos: Estudos Contemporâneos da Subjetividade, Campos dos Goytacazes, v. 2, n. 2, p. 291-305, 2012.

LIMA, Luciana D.; MACHADO, Cristiani V.; GERASSI, Camila D. O neoinstitucionalismo e a análise de políticas de saúde: contribuições para reflexão crítica. In: MATTOS, Ruben A.; BAPTISTA, Tatiana W. F. (orgs.). Caminhos para a análise de políticas de saúde. Rio de Janeiro: IMS/Ensp/EPSJV, 2011. (Projeto: Material Análise de Políticas Públicas de Saúde, Rio de Janeiro: Faperj, IMS/Uerj, Ensp/Fiocruz, 
EPSJV/Fiocruz, 2011. Disponível em: <http:// site.ims.uerj.br/pesquisa/ccaps/?p=42> Acesso em: nov-2017

LIPIETZ, Alain. As relações capital-trabalho no limiar do século XXI. Ensaios Fundação de Economia e Estatística Siegfried Emanuel Heuser, Porto Alegre, v. 12 n. 1, p. 101-130, 1991.

MACHADO, Maria H. Sociologia de las profisiones: um nuevo enfoque. Educacion Médica Salud, Washington, v. 25, n. 1, p. 28-36, 1991.

MACHADO, Maria H. Macro e micro: os novos desafios da sociologia no campo da saúde. In: CANESQUI, Ana M. (org.). Dilemas e desafios das ciências sociais na saúde coletiva. São Paulo: Hucitec; Rio de Janeiro: Abrasco, 1995. p. 83-93.

MACHADO, Maria H. et al. O mercado de trabalho em saúde no Brasil: estrutura e conjuntura. Rio de Janeiro: ENSP, 1992.

MARINHO, Marcelo J. M. C. Profissionalização e Credenciamento: a política das profissões. Rio de Janeiro: Senai. 1986.

MARQUES, Eduardo C. Notas críticas à literatura sobre Estado, políticas estatais e atores políticos. Revista Brasileira de Informação Bibliográfica em Ciências Sociais, Rio de Janeiro, n. 43, p. 67-102, $1^{\circ}$ sem. 1997.

MATTOSO, Jorge E. L. Emprego e concorrência desregulada: incertezas e desafios. In: OLIVEIRA, Carlos A. B.; MATTOSO, Jorge E. L. (orgs.). Crise e trabalho no Brasil: modernidade ou volta ao passado? São Paulo: Scritta, 1996.p. 27-54.

MENDES-GONÇALVES, Ricardo B. Medicina e história: raízes sociais do trabalho médico. 209 p. Dissertação (Mestrado) - Faculdade de Medicina, Universidade de São Paulo, São Paulo, 1979.

MOLINIER, Pascale. Psychodynamique du travail et rapports sociaux de sexe. Travail et Emploi. n. 97, Janvier, 2004, p. 79-91. Disponível em: $<$ https://travail-emploi.gouv.fr/publications/ Revue_Travail-et-Emploi/pdf/97_2480.pdf> Acesso em: julho-2014.
MOORE, Wilbert. The professions: roles and rules. New York: Russel Sage Foundation, 1970.

NOGUEIRA, Roberto P. Anotações sobre a trajetória e os problemas da pesquisa em recursos humanos de saúde. Rio de Janeiro, 1992. (mimeo).

NOGUEIRA, Roberto P. O trabalho em saúde hoje: novas formas de organização. In: NEGRI Barjas; FARIA, Regina; VIANA, Ana L. A. (orgs.) Recursos humanos em saúde: política, desenvolvimento e mercado de trabalho. Campinas: Instituto de Economia/Unicamp, 2002. p. 257- 273.

OLIVEIRA, Eliane S. Indicadores essenciais para gestão do trabalho. Divulgação em Saúde para Debate, Rio de Janeiro, n. 45, p. 126-142, maio 2010.

OLIVEIRA, Eliane S.; MACHADO, Maria H. Para medir o trabalho em saúde no Brasil: principais fontes de informações. Divulgação em Saúde para Debate, Rio de Janeiro, n. 45, p. 105-125, maio 2010.

OLIVEIRA, Simone S. Um olhar sobre a saúde a partir da dimensão gestionária do trabalho: contradições e ambiguidades no telemarketing. 2007. 184 f. Tese (Doutorado em Saúde Pública) Escola Nacional de Saúde Pública Sergio Arouca, Fundação Oswaldo Cruz, Rio de Janeiro, 2007.

OLIVEIRA, Simone; ALVAREZ, Denise; BRITO, Jussara. A dimensão gestionária do trabalho: aspectos da atividade do cuidado. Ciência \& Saúde Coletiva, Rio de Janeiro, v. 18, n. 6, p. 1.581-1.589, jun. 2013.

ORGANIZACIÓN PANAMERICANA DE LA SALUD (OPAS). División de Desarrollo de Sistemas y Servicios de Salud. Programa de Desarrollo de Recursos Humanos, Gestión de Recursos Humanos en Las Reformas Sectoriales en Salud: cambios y oportunidades. QUINTANA, Pedro B.; CAMPOS, Francisco; NOVICK, Marta (orgs.). Washington, 1996.

PAIM, Jairnilson S. Recursos humanos em saúde no Brasil: problemas crônicos e desafios agudos. São Paulo: Faculdade de Saúde Pública, Universidade São Paulo, 1994 
PEDUZZI, Marina; SCHRAIBER, Lilia B. Workshop: mapeamento de projetos de pesquisa e de intervenção sobre recursos humanos em saúde, no âmbito nacional. Interface: Comunicação, Saúde, Educação, Botucatu, v. 4, n. 7, p. 149-152, 2000.

PEDUZZI, Marina; SCHRAIBER, Lilia B. Processo de trabalho (verbete). In: PEREIRA, Isabel B.; LIMA, Julio C. F. Dicionário de educação profissional em saúde. 2. ed. Rio de Janeiro: EPSJV, 2008. p. 320-328.

PINTO, Isabela C. M. et al. Trabalho e educação em saúde no Brasil: tendências da produção científica entre 1990-2010. Ciência \& Saúde Coletiva, Rio de Janeiro, v. 18, n. 6, p. 1.525-1.534, jun. 2013.

ROCHA, Carlos V. Neoinstitucionalismo como modelo de análise para as políticas públicas: algumas observações. Civitas, Porto Alegre, v. 5, n. 1, p. 11-28, jan.-jun. 2005.

SANO, Hironobu; ABRUCIO, Fernando L. Promessas e resultados da nova gestão pública no Brasil: o caso das organizações sociais de saúde em São Paulo. Revista de Administração de Empresas - RAE, São Paulo, v. 48, n. 3, p. 64-80, jul.-set. 2008.

SCHRAIBER, Lilia B.; PEDUZZI, Marina. Tendências e possibilidades da investigação de recursos humanos de saúde no Brasil. Educacion Médica y Salud, Washington, v. 27 n. 3, p. 295-313, 1993.

SKOCPOL, Theda. Bringing the State back in: strategies of analysis in current research. In: EVANS, Peter D.; RUESCHEMEYER, Dietrich; SKOCPOL, Theda. Bringing the State back in. Cambrige: Books Online, 2012. Disponível em: <http://catdir.loc.gov/catdir/samples/ cam034/85004703.pdf>. Acesso em: 20-10-2017.

SCHWARTZ, Yves. A comunidade científica ampliada e o regime de produção de saberes. Trabalho \& Educação, Belo Horizonte, n. 7, p. 38-46, jul.-dez. 2000.

SCHWARTZ, Yves. Disciplina epistêmica, disciplina ergológica: paideia e politeia. Pro-
-Posições, Campinas, v. 13, n. 1, p. 126-149, jan.-abr. 2002.

SCHWARTZ, Yves. Conceituando o trabalho, o visível e o invisível. Trabalho, Educação e Saúde, Rio de Janeiro, v. 9, supl. 1, p. 19-45, 2011.

SCHWARTZ, Yves; DUC, Marcelle; DURRIVE, Louis. O homem, o mercado e a cidade. In: SCHWARTZ, Yves; DURRIVE, Louis (orgs.). Trabalho \& ergologia: conversas sobre a atividade humana. Niterói: EdUFF, 2010. p. 247-277.

SILVA, Luiz M. O. Organizações e relações de trabalho no setor de serviços de saúde brasileiro. 128f. Dissertação (Mestrado em Desenvolvimento Econômico) - Instituto de Economia, Universidade Estadual de Campinas, Campinas, 2006.

SOUZA, Celina M. Políticas públicas: questões temáticas e de pesquisa. Caderno $\mathrm{CRH}$, Salvador, v. 16, n. 39, p. 11-24, jul.-dez. 2003.

THELEN, Kathleen; STEINMO, Sven. Historical institutionalism in comparative politics. In: STEINMO, Sven; THELEN, Kathleen; LONGSTRETH, Frank(eds.). Structuring politics: historical institutionalism in comparative analysis. Cambridge: Cambridge University Press, 1992. DOI: https://doi.org/10.1017/ CBO9780511528125

VIANA, Ana L. D.; BAPTISTA, Tatiana W. F. Análise de políticas de saúde In: GIOVANELLA, Lígia et al. (orgs.). Políticas e sistema de saúde no Brasil. 1. reimp. Rio de Janeiro: Editora Fiocruz, Cebes, 2009, p. 65-104.

WILENSKY, Harold L. The Professionalization of Everyone? In: GRUSKY, Oscar \& MILLER, George (orgs.), The Sociology of Organizations: Basics Studies. New York: The Free Press, 1970. p. 70-137.

VIEIRA, Carlos E. C.; BARROS, Vanessa A.; LIMA, Francisco P. A. Uma abordagem da psicologia do trabalho: na presença do trabalho. Psicologia em Revista, Belo Horizonte, v. 3, n. 1, p. 155-168, jun. 2007. 


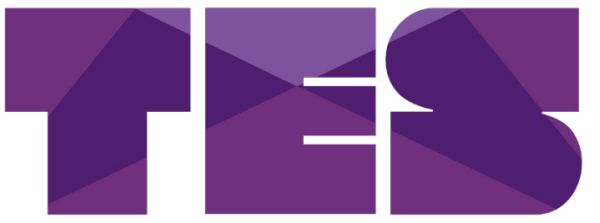

\section{Trabalho, Educação e Saúde}

ERRATA

DOI: $10.1590 / 1981-7746-$ sol00290

Trabalho, Educação e Saúde, 2020, v.18, suplemento 1 ISSN 1981-7746 DOI: 10.1590/1981-7746-sol00290 e-location: e00290122

No artigo <ABORDAGENS DO TRABALHO NO SETOR PÚBLICO DE SAÚDE: UMA REVISÃO NARRATIVA DA LITERATURA>, com número de DOI: <https://doi.org/10.1590/1981-7746-sol00256>, publicado no periódico < Trabalho, Educação e Saúde>, 2020; <18(s1):e0025688>, na página $<1>$, disponível em: <https://www.scielo.br/pdf/tes/v8s1/1678-1007-tes-18s1-e0025688.pdf>

Onde se lia: "https://orcid.org/0000-0001-5477-6216"

Leia-se: "https://orcid.org/0000-0002-1477-749X" 